\title{
Use of technical and economical parameters for evaluating dairy cow ration efficiency
}

\author{
Francesco Adduci, Cristiana Labella, Mauro Musto, Carmine D’Adamo, Pierangelo Freschi, \\ Carlo Cosentino \\ School of Agricultural, Forest, Food and Environmental Sciences, University of Basilicata, Potenza, \\ Italy
}

\begin{abstract}
The aim of this study was the development of a model for evaluating dairy cow ration efficiency. This model took into account technical, metabolic, and economic parameters, which were divided into two main categories: input and output. Feeding (food administered and its nutritional characteristics) was considered as the input parameter. The output indicators were directly or indirectly correlated with feeding, and included: quality and quantity of milk, body condition score, live weight, reproductive parameters, incidence of animal diseases (laminitis), undigested fraction, fecal consistency, feed efficiency (FE), and income over feed cost (IOFC). The model was validated using ten dairy farms located in the northwest of Basilicata. The farms were divided into two groups (A and B) as a function of the urea level in bulk milk. In Group A, the urea level was between 25 and $31 \mathrm{mg} / 100$ $\mathrm{mL}$ milk, whereas, in Group B, the range was $21-22.5 \mathrm{mg} / 100 \mathrm{~mL}$ milk. The model showed that the values of reproductive parameters were worse in Group A than in Group B. However, the Group A showed better milk qualitative and quantitative characteristics, such as a high average production per head (28.15 vs $26.93 \mathrm{~kg}$ ), and a high fat (3.92 vs
\end{abstract}

Correspondence: Francesco Adduci, School of Agricultural, Forest, Food and Environmental Sciences (SAFE), University of Basilicata, via dell'Ateneo Lucano 10, 85100 Potenza, Italy.

Tel.: +39.0971.205044 - Fax: +39.0971.205604.

E-mail: francesco.adduci@unibas.it

Key words: Fecal consistency; feed efficiency; milk margin; undigested fraction; urea.

Acknowledgements: this research was supported by Regione Basilicata MIBAF Project PIF - Rural Development Programme 2007-2013, Fund FEASR, Board 1, Measure 124-PIF Green Farms: Together to raise, transform, marketing and grow in quality with Green Farms.

Contributions: the authors contributed equally.

Received for publication: 24 April 2015.

Revision received: 29 June 2015.

Accepted for publication: 1 July 2015.

(C) CopyrightF. Adduci et al., 2015

Licensee PAGEPress, Italy

Italian Journal of Agronomy 2015; 10:682

doi:10.4081/ija.2015.682

This article is distributed under the terms of the Creative Commons Attribution Noncommercial License (by-nc 3.0) which permits any noncommercial use, distribution, and reproduction in any medium, provided the original author(s) and source are credited.
$3.71 \%)$ and protein (3.53 vs 3.37\%) content of bulk milk. Moreover, the highest values of FE (1.45 vs $1.35 \mathrm{~kg}$ milk/kg dry matter) and IOFC (6.07 vs $5.32 €$ ) were found in Group A. The model clearly showed that the administration of unbalanced rations, based on the physiological stage of the animals, negatively affected both the qualitative and quantitative characteristics of milk, as well as the reproductive performances. The administration of unbalanced rations for the energy/protein content caused dysmetabolic syndromes, which led to a reduction of both FE and IOFC. This, ultimately, caused a fall in the overall farm profitability.

\section{Introduction}

The concept of correct rationing, applied routinely by food technicians, is based on several indicators to assess its efficiency, in terms of both production performances and quality of the product. A proper business strategy depends on the exact knowledge of the production process in order to verify the effectiveness of management strategies and of obtained results. In recent years, the search for the food minimum cost has been replaced by the determination of the maximum feed efficiency (FE) (maximizing the difference between the proceeds from the milk sales and the cost of feeding).

FE is a key parameter to assess the milk production of livestock according the intake of dry matter. This parameter allows comparing the revenue generated from the milk sale based on the amount of dry matter (DM) ingested by the animal (Hutjens, 2001). A study performed by the University of Illinois (Hutjens, 2001) showed that normal values of FE (or dairy efficiency) generally range between 1.3 and $1.5 \mathrm{~kg}$ of fat corrected milk (FCM)/kg DM intake (FCM to $3.5 \%$ of fat), while values less than $1.3 \mathrm{~kg}$ of FCM/kg DM intake are considered too low, showing a high dry matter intake, a decrease in milk production or a change in the normal feed ration. Conversely, values greater than $1.5 \mathrm{~kg}$ of FCM/kg DM intake are considered excellent, indicating better farm efficiency and profitability. Due to the continuous drop in prices and to the increased cost of raw food, the maximization of FE is the assumption that every farm should pursue. This is achieved through careful feed management meant as both the rationing and the quality of given feed.

Errors in feeding management of dairy cattle should be quickly identified and corrected, as they can be detrimental not only on the productivity of the animals, but also on their health and fertility, with consequent negative effects on the overall farm profitability. The income over feed cost (IOFC) is an economic parameter closely related with the FE; it is useful for comparing the milk revenue less food costs of the bovine ration of each breeding. According to the College of Agricultural Sciences (Penn State Extension, 2009), food costs represent up to $70 \%$ of the total cost for milk production; the remaining $30 \%$ is represented by other management costs. The main variables that influence the IOFC are: the cost of feed, the FE, total ingestion of dry 
matter, and the price of milk, with the latter being a crucial component for the final result. The calculation of IOFC can be considered as simple yet accurate: it considers only feed costs that represent the greatest input in the budget, to whom are subtracted the revenues generated from the sale of milk. This leads to a good compromise for the farmer in terms of easy calculation and reliability of results. The IOFC does not replace the farm's economic budget, but is a valuable tool of deepening, in real time, on food management (St-Pierre, 2008).

In the present study, a new model for assessing both direct and indirect effects of certain management practices on the overall farm performances and profitability is presented. The underpinning logic of this model is based on an event cause-effect relationship between the input and output data, in which explanations, recommendations, and suggestions from literature in the field allow to identify the problems in a farm, to link them to their underlying causes and consequences, and, finally, to propose corrective measures. In particular, the application of this model allows discerning the errors due to feeding management from those related to sanitary or environmental aspects. To this aim, in the present study, feeding was considered as the input parameter, whereas multiple indicators, which were statistically correlated with some factors of rationing, were considered as output.

\section{Materials and methods}

\section{Sample description}

The test was conducted by identifying 10 among the 70 farms belonging to the Cooperativa Latte Verdi Fattorie. These farms were representative of the medium-hilly rearing areas in the North West of Basilicata, in terms of number of heads, rearing system, and for both supply and delivery system of the raw materials. The rearing system adopted by the farms was free stall with rest area in bunks. The main farm characteristics are listed in Table 1. The large number of lactating cows ranged from a minimum of 28 to a maximum of 110 mares, all Italian Friesian breed with an average live weight of $646.60 \mathrm{~kg}$. The heifer internal replacement was $80 \%$. The average age at first birth was 27.57 months. The average distance from birth, recorded during the monitoring, was between 170 and 254 days. The administration of the feed ration was based on the use of the unifeed.

In each farm, the following input and output parameters were evaluated.

\section{Input parameters}

\section{Nutritional and physical assessment of feed}

The unifeed sampling was carried out by lane feeding into four different points before animals entering. The physical quality evaluation was performed by using Penn State forage particle separator
(Heinrichs and Kononoff, 2002) in order to determine the physically effective neutral detergent fiber (peNDF) really contained in the individual rations. Following Grant and Cotanch (2005), peNDF was calculated multiplying the NDF by the fraction of the feed retained by the sieve of $1.18 \mathrm{~mm}$ (mesh diameter).

The analysis of the unifeed nutritional characteristics, performed by NIRSYSTEM 5000 (Foss Electric A/S, Hillerød, Denmark), for both individual unifeed and for farm, were processed by the software Cpm Dairy Analyzer ver. 3.0.7a (University of Pennsylvania School of Veterinary Medicine). This allowed evaluating the ruminal kinetics considering, among the several parameters reported by the model, those relating to the balance in nitrogen in the rumen and to carbohydrates [structural: NDF, peNDF; non-structural: non-fibrous carbohydrates (NFC)]. The average daily intake of dry matter was calculated using data on daily consumption supplied by farmers.

\section{Output parameters}

\section{Evaluation of milk qualitative characteristics}

The evaluation in protein, fat, and lactose content was performed by Milkoscan FT 6000 (Foss Electric A/S) according to the International Dairy Federation standard (ISO, 2000), whereas dry matter and ash content were measured using methods of the Association of Official Analytical Chemists (AOAC, 1990). In addition, somatic cells was determined using a Fossomatic 5000 (Foss Electric A/S). The urea content was performed by instrument EFA 2000 (HAMILTON EUROCHEM; reference standard ISO 14637:2004/IDF 195:2004) (ISO, 2004). The total bacterial count was carried out by BactoScan ${ }^{\mathrm{TM}} \mathrm{FC}$ (Foss Electric A/S).

\section{Performances criteria evaluation}

The average live weight of the lactating cows was calculated by weighing a representative sample of animals for the heifer and cow category. Body condition score (BCS) was assessed by following the Ferguson's methodology (1994). The lameness incidences (laminitis of non-traumatic origins) for each farm was calculated by the measurements performed during the diagnosis of farm veterinarian.

The fecal consistency (FC) was evaluated using a scale from 1FC to $5 \mathrm{FC}$, in according to the methodology of manure evaluation guide (Hall, 2002).

The undigested fraction (UF) was evaluated by sieving stool samples with a sieve of $18 \mathrm{~cm}$ in diameter and $10 \mathrm{~cm}$ depth (mesh $1.6 \mathrm{~mm}$ ). The sample was collected with disposable cups with a capacity of $250 \mathrm{~mL}$ in according to Dell'Orto and Savoini's protocol (2005), in which five categories (from 1UF to 5UF) can be identified on the basis of the casuistry reported by manual.

The reproductive efficiency was evaluated considering the following parameters: days open [DO = Calving-to-conception interval]; average pregnancy per service (APPS); Calving interval (CI, days), conception rate $(\mathrm{CR}$, calculating the percentage of cows that conceive after a sin-

Table 1. Main farm characteristics.

\begin{tabular}{lccccccccccc} 
Farms & 1 & 2 & 3 & 4 & 5 & 6 & 7 & 8 & 9 & 10 \\
Number of lactating cows & 110 & 70 & 56 & 72 & 32 & 45 & 28 & 64 & 85 & 52 & 35 \\
Average effective annual turnover rate $\%$ & 33 & 31 & 30 & 31 & 34 & 36 & 31.5 & 32 & 34 \\
\hline Distance from birth (the time of data collection) & 173 & 254 & 200 & 250 & 220 & 170 & 185 & 203 & 219 & 220 \\
Age of first birth & 24.7 & 27 & 26 & 28 & 27 & 29 & 28 & 29 & 28 & 29 \\
\hline Average live weight of lactating cows (kg) & 630 & 640 & 655 & 645 & 660 & 645 & 658 & 640 & 645 & 645 \\
\hline
\end{tabular}


gle service); service rate [SR = APPS / (D0 - voluntary waiting period) / 21, the percentage of eligible cows bred during a 21-day period that are at risk to receive a breeding], pregnancy rate $(\mathrm{PR}=\mathrm{CR} \times \mathrm{SR}$, defined as the number of eligible cows (i.e., non-pregnant cows past the voluntary waiting period in a herd that conceive every 21 days).

\section{Evaluation of income parameters}

The technical and economic efficiency assessment of the feed ration was performed by calculating FE and IOFC; the IOFC measures the difference between milk revenues and feed costs (Equation 1):

$\mathrm{IOFC}(€ /$ cow/day $)=$ Pmilk $\times(\mathrm{DAMP} / 100)-\mathrm{DFC}$

where:

Pmilk is the all-milk price $(€ / \mathrm{q})$;

DAMP is daily average milk production ( $\mathrm{kg} / \mathrm{cow} / \mathrm{day})$;

DFC is daily feed costs (€/cow/day).

DFC is the daily feedstuffs cost required to produce the amount of milk reflected in DAMP.

Milk margin (MM) response reflects the profit if additional kilogram of milk can be achieved; it is defined as follows (Equation 2):

MM $(€ / \mathrm{kg})=$ Pmilk - DFC $\times 100 /$ DAMP

where:

Feed cost per kilogram of dry matter is a useful term when comparing similar regions, breeds, and levels of milk production.

The FE (also referred to as dairy efficiency) can be defined as kilograms of 3.5\% FCM (Equation 3) produced per kilogram of DM consumed as reported by Hutjens (2007):

$3.5 \% \mathrm{FCM}=(0.4324 \times \mathrm{kg}$ of milk $)+(16.216 \times \mathrm{kg}$ of fat milk $)$

\section{Results}

\section{Input}

Input parameters showed that the average intake of dry matter per head, recorded in the 10 farms, was $20.68 \mathrm{~kg} /$ day (Supplementary File, Table 2).

The processing of individual food rations with the software $C P M$ dairy allowed to interpret the kinetic rumen of animals per farm, defining the following means characteristics. The average content in rumen degradable protein (RDP) of DM was $11.01 \%$, with a minimum of $9.00 \%$ and a maximum of $14.00 \%$ (Supplementary File, Table 2); the average content in soluble protein (expressed in \% of crude protein) was $28.88 \%$. The ruminal nitrogen balance, estimated by the model, showed an average quantity of free nitrogen in the rumen level, in the form of $\mathrm{NH}_{3}$ and peptides, equal to $110.00 \%$ and $100.70 \%$ of total average requirement, respectively; the average ratio of net protein and metabolizable protein was $61.9 \%$. The average intake in lysine and methionine (expressed in \% of metabolizable protein) was $5.98 \%$ and $2.04 \%$, respectively; the methionine/lysine ratio was 2.73 (Supplementary File, Table 2). With regard to structural carbohydrates, the average levels in NDF (\%DM) and peNDF (\%DM) of provided diets was $34.77 \%$ and 25.15 , respectively. The NDF made with fodder was on average equal to $68.90 \%$ total NDF. The average level in fermentable NDF (\%DM), estimated by the model, was $18.72 \%$, in a range between $15.60 \%$ and $22.00 \%$. The content of soluble fibre was $6.29 \%$ (\%DM). The average level of NFC (\%DM) was $40.47 \%$, with values ranging from a minimum of $38.70 \%$ to a maximum of $43.00 \%$. The starch content and starch fer- mentable average was $26.78 \%$ and $18.48 \%$ (\%DM), respectively (Supplementary File, Table 2).

From physical analysis obtained by sieving unifeed, the particles distribution was recorded in various foods contained in the rations administered in each single farm. The average values of the sample showed a particle distribution of $7.81 \%, 31.81 \%, 47.00 \%$, and $13.38 \%$, respectively for the plates upper, middle, lower and bottom (Supplementary File, Table 3).

\section{Output}

The average milk production in the 10 farms, referred to the year 2013, was $27.42 \mathrm{~kg} / \mathrm{cow} / \mathrm{day}$ (Supplementary File, Table 4); the content of fat, protein, and lactose was $3.79,3.43$, and $4.83 \%$, respectively. The content of urea was $25.06 \mathrm{mg} / 100 \mathrm{~mL}$ of milk [milk urea nitrogen (MUN) $11.50 \mathrm{mg} / 100 \mathrm{~mL}$ of milk], whereas total bacterial count and the content in somatic cells were 181,800 and 64,600 , respectively. BCS of lactating subjects was 3.28 , whereas the incidence of lameness (laminitis of non-traumatic origins) was 9.29\% (Supplementary File, Table 5). Regarding the FC (Supplementary File, Table 6), only 36.78\% of faeces were classified as belonging to the optimal category (3FC). According to the UF analysis (Supplementary File, Table 7), 43.01\% of faeces were in the optimal category (1UF).

Concerning reproductive data (Supplementary File, Table 8), the average calving interval was 418.80 days, with an average interval D0 of 136.80 days. The average values regarding the conception rate, the service rate, the pregnancy rate and APPS were $47.80 \%, 37.10 \%, 17.50 \%$ and 1.98, respectively (Supplementary File, Table 8).

The calculation of IOFC and income parameters is shown in Supplementary File (Table 8). The IOFC average value ( $€ /$ cow/day) was $5.62 €$ (Supplementary File, Table 9), with values ranging from a minimum of $4.25 €$ to a maximum of $6.36 €$. The average FE was 1.39 , with a minimum of 1.26 and a maximum of 1.54. The mean value of the MM was $0.20 € / \mathrm{kg}$ of milk and a feed cost of $0.30 €$ per kilogram of dry matter (Supplementary File, Table 9).

\section{Discussion}

The value related to the milk production found in this study was well below the national value published by Associazione Nazionale Frisona Italiana (ANAFI) in 2013 (27.42 kg vs $30.46 \mathrm{~kg}$ ). By contrast, the contents of fat (3.71\% vs $3.80 \%)$ and proteins (3.32\% vs $3.43 \%)$ for proteins were higher than those reported by ANAFI. The values of somatic cells and total bacterial count were lower than the maximum amount allowed by the regulations for raw milk (Reg. EC 853/2004; European Commission, 2004). The content of urea in milk also fell within the optimal range reported in the literature $(25-28 \mathrm{mg}$ urea/100 mL of milk; MUN 11.5-12.84 mg/100 mL of milk) (Mariani et al., 1992).

The comparison between the data relative to the measured parameters (milk production quantity, fat and proteins content) and the average reference standard, adopted for the assessment of individual food rations, showed some critical issues confirmed by the analysis of field. For an effective and comprehensive discussion of the problems encountered in field research, the farm sample was divided into two homogeneous groups by urea level in milk. The Group A included 4 farms (2-4-5-6), which had a urea content of $25-31 \mathrm{mg} / 100 \mathrm{~mL}$. The Group B was represented by 6 farms (1-3-7-8-9-10) characterized by a urea content of $21-22.5 \mathrm{mg} / 100 \mathrm{~mL}$.

\section{Group A}

The farms belonging to this group had a food imbalance due to a 
higher degradable nitrogen level in the rumen than fermentable carbohydrates provided by diet. Ruminal nitrogen balance, estimated by the model, confirmed and highlighted a level of $\mathrm{NH}_{3}$ (124\%) and peptides (110.5\%) higher than the target value (110\% of requirements). In fact, the rations administered to mares had a content in RDP and in fermentable carbohydrates, respectively, upper (13.30\% vs 11\%) and lower (15.70\% vs 21\%) than the target value reported (Supplementary File, Table 2). The quantity of ammonia that was produced, and the amount that resulted from conversion to urea, directly reflected both dietary RDP and the availability of fermentable carbohydrates to support microbial growth and protein synthesis (Butler, 1998). This could explain the higher average urea level in bulk milk recorded in Group A than in Group B (Roseler et al., 1993). The average quantity of urea was $30.10 \mathrm{mg} / 100 \mathrm{~mL}$ of milk (MUN $13.81 \mathrm{mg} / 100 \mathrm{~mL}$ of milk); this value was higher than the optimal range reported by Mariani et al. (1992). Moreover, excess rumen available nitrogen requires energy (urea cost) to convert ammonia to urea and to excrete urea. In addition, rations with excess rumen available nitrogen not only contribute to environmental pollution, but they also use energy that could be channeled to productivity (Roseler et al., 1993).

Stool samples fell mainly in the first two score categories of FC (1FC, $2 \mathrm{FC}$ ), except the farm n. 2, in which feces belonging to the categories $4 \mathrm{FC}$ and $5 \mathrm{FC}$ were also observed (high consistency for lactating dairy cows), probably as consequences of both an fiber excess and a low water intake for a small number of cows in the group. According to the model FC assessment, the high presence of feces falling in the first two score classes was directly related to unbalanced rations in terms of protein or starch (Hall, 2002). The data on the rationing parameters would lead to exclude the excess in non-structural carbohydrates, and to debit the detected dysmetabolic syndrome to an excess of degradable nitrogen at the rumen level. The hypothesis is confirmed by UF, from which does not emerge an excessive presence of undigested food in the stool due to an excess of fermentable carbohydrates (Hall, 2002). The observed imbalance food could also justify the fertility problems encountered in farms of Group A. As seen in the Table 3 (Supplementary File), these farms of Group A were also characterized by the worst reproductive parameters.

The data obtained are confirmed by the literature about the negative effects on the reproductive sphere of mares caused by high levels of urea in milk (Butler, 1998). In fact, the Group A compared to B showed a greater average CI (441.50 vs 403.67 days), D0 average (159.50 vs 121.67 days), as well as a higher APPS (2.59 vs 1.57). In addition, the Group A showed lower average values in terms of conception rate (39.50\% vs $53.33 \%)$ and pregnancy (16.25\% vs $18.33 \%)$ (Supplementary File, Table 8 ). The average efficiency rate in the detection of SR in Group A was higher than both the average for the entire sample (37.10\%) and Group B (41.25\% vs 34.33\%), confirming what sustained before (i.e., that the low level of reproductive efficiency of breeding was not only due to management errors during the detection phase of the $\mathrm{SR}$, but also to errors in the feeding management).

\section{Group B}

In this group, the average level of urea in milk was $21.69 \mathrm{mg} / 100 \mathrm{~mL}$ milk (MUN $9.95 \mathrm{mg} / 100 \mathrm{~mL}$ milk). The parameters related to the rationing showed a low content of RDP and levels of starch and starch fermentable higher than target values provided by the model guidelines. The ruminal balance in ammonia and peptides, estimated with the CPM Dairy Beta, highlighted a deficiency in degradable nitrogen in the rumen level (Supplementary File, Table 2). Concerning the structural carbohydrates, the level of average NDF fell within the expected range. Conversely, the level in peNDF average was lower than the optimum levels reported by Mertens (1997). The uniformity evaluation of the unifeed (Supplementary File, Table 3), associated with the calculation of peNDF, showed the lowest physical effect among the rations given in all farms. This is deduced from the highest average percentage of unifeed collected by the bottom plate sieve compared to the average of the whole sample (Bottom) (16.9 vs 13.38\%). This is most likely due to more time chopping and mixing unifeed inside the mixer wagon, as well as a greater level of concentrates in the ration. The high level of fermentable carbohydrates (starch fermentable) to rumen level associated with a low level in real peNDF may predispose the animal to a state of sub-acute acidosis (Nocek, 1997).

As shown by the parameters concerning the faecal consistency, Tables 6 and 7 (Supplementary File), in these farms a greater average percentage of unusual faeces was detected, than the average of the entire sample, falling in both second category score of the FC (2FC; $29.42 \%$ vs $28.31 \%$ ), and in the second category score of the UF (2UF; $41.77 \%$ vs $31.66 \%$ ). These data confirmed the fermentation imbalance and the reduced digestibility of the ration, due to a high ruminal passage rate of food (Hall, 2002). In fact, a low peNDF intake involves an increase in the speed of food transit in the rumen, because it reduces the ability of the fibre to trap the elementary smaller particles, resulting in an increase of all the constants of passage (Kp), and in a reduction of the both degradability (Kd) and of the overall ration digestibility (Grant, 1997). These indirect indicators of rumen pH are also confirmed by the percentage of lameness caused by non-traumatic laminitis. In fact, the average percentage of laminitis was $10.95 \%(9.29 \%$ mean of total sample; $6.80 \%$ mean of Group B), with values ranging from a minimum of $5.40 \%$ to a maximum of $15.00 \%$ (Supplementary File, Table 5).

It is well known that the hoof pathologies, such as laminitis, may be caused by both histamine and bacterial endotoxins, both released in the rumen or in the intestine as result of dismicrobism conditions, such as both ruminal and intestinal acidosis states (blind-colon) (Nocek, 1997).

The dysmetabolic syndrome allowed us to explain the lower fat content in milk observed in Group B than both the average of the entire sample (3.71\% vs 3.80\%), and the average of Group A (3.71\% vs $3.92 \%)$. This condition was probably due, as reported in the literature, to the decrease in rumen $\mathrm{pH}$ resulting from an excess of fermentable carbohydrates (AbuGhazaleh et al., 2005).

\section{Parameters income}

IOFC was closely related to the index of food conversion, because it is a function of the direct relationship between the feeding cost and of the produced milk amount. The IOFC maximization was obtained by pursuing the best conversion of dry ingested matter in kg of produced milk. The average cost of the sample was $5.62 €$ (Table 9, Supplementary File), which was less [6.24 €/cow/day (minimum of $3.24 € /$ cow/day; maximum of $11.76 € /$ cow/day)] than that found by the Sales and Service Technical farmers in Lombardy region (the Italian region of reference for the production of cow milk). This difference is due to both an increase in the cost of food commodities and to a change (positive or negative) in the sale price of the milk at the barn.

The average cost of feeding recorded in the 10 farms was 0.30 $€ / \mathrm{kg} / \mathrm{DM}$. This datum is optimal in comparison with the results obtained from surveys conducted in Lombardy region on 80 farms participating to Progetto Economia (Campiotti, 2014).

FE average was $1.39 \mathrm{~kg}$ milk/kg DM, with a minimum of 1.26 and a maximum of 1.54 . This value can be also considered as satisfactory, because it falls within the optimal range 1.3-1.5 reported by the study of the University of Illinois (Hutiens, 2001). The average FE takes on a positive value, even in comparison with the reference value $1.38 \mathrm{~kg}$ milk/kg DM calculated in relation to average milk production per head 
(St-Pierre, 2008). The average value of MM was $0.20 € / \mathrm{kg}$ milk, with a marginal cost of feeding amounted to $0.13 €(0.44 \mathrm{~kg}$ DM/L milk $\times 0.30$ $€ / \mathrm{kg} \mathrm{DM})$. Therefore, any farm improvement that leads to production greater than $1 \mathrm{~L}$ of milk at a cost less than $0.20 €$ (MM value), can be considered positive, because it determines an increase of the net farm income. In detail, the comparison between the two groups showed the negative correlation between the reduction of the overall digestibility and the worsening of $\mathrm{FE}$, increasing the feeding cost and reducing IOFC (Hutjens, 2010). For the same milk price ( $0.43 € / \mathrm{kg}$ milk), the comparison of the average income between the two groups confirmed lower income, meant as IOFC amount average daily per cow milking, in Group B than in Group A (5.32 vs 6.07). This datum comes from the lower Feed Efficiency means (1.35 vs 1.45) recorded in Group B than in Group A. The same pattern was observed for the MM $(0.20 € / \mathrm{kg}$ milk $v s$ $0.22 € / \mathrm{kg}$ milk). Furthermore, the higher food cost of Group B than Group A ( $0.30 € / \mathrm{kg}$ DM vs. $0.29 € / \mathrm{kg}$ DM) also helps to increase the difference recorded in IOFC average. This study confirms the direct correlation between the technical efficiency of the food ration with the IOFC. Moreover, it also highlights the impact of the errors in the dietary management on business farm margins.

\section{Correlations - Model validations}

In order to validate the model, a correlation analysis, including all the input and output variables, was performed. The urea content in milk was significantly correlated with the content of the rations in RDP $(\mathrm{r}=0.912 ; \mathrm{P} \leq 0.001)$ (Supplementary File, Table 10) in agreement with what is reported in the literature about the relationship between protein and urea content (Roseler et al., 1993).

There were significant correlations between the urea content and parameters related to the nitrogen ruminal level estimated by the model (Supplementary File, Table 11), and between the urea content of the milk and reproductive parameters: the $\mathrm{CI}(\mathrm{r}=0.928$; $\mathrm{P} \leq 0.001)$, D0 $(\mathrm{r}=0.928 ; \mathrm{P} \leq 0.001)$, the ASSP $(\mathrm{r}=0.961 ; \mathrm{P} \leq 0.001)$ and SR $(\mathrm{r}=-0.691$; $\mathrm{P} \leq 0.05$ ) (Supplementary File, Table 10). This was in agreement with the negative effects on the reproductive performance due to high levels of urea highlighted by Butler (1998).

The content in peNDF total (Supplementary File, Table 12) of the rations was positively correlated with the feed fraction held in the middle plate of the sieve $(\mathrm{r}=0.768 ; \mathrm{P} \leq 0.01)$, and with the fat content in milk $(\mathrm{r}=0.701 ; \mathrm{P} \leq 0.05)$. The latter correlation is fully confirmed in literature by Allen (1997) about positive correlation between the physically effective fibre content and fat content in milk. The starch content of the rations was positively correlated with the percentage of faeces falling in the category 2UF $(\mathrm{r}=0.823 ; \mathrm{P} \leq 0.01)$, and with the percentage of unifeed left over in the bottom plate of the sieve $(\mathrm{r}=0.704 ; \mathrm{P} \leq 0.05)$ (Supplementary File, Table 12), since the content of the last plate (Bottom pan) is closely related to the quantity of concentrates fed in unifeed. Conversely, the starch content was negatively correlated $(\mathrm{r}=-0920 ; \mathrm{P} \leq 0.001)$ with the average content of fat in bulk milk. Such negative correlation had a significance higher than that found between the content in peNDF, and the fat in the milk; this is in agreement with AbuGhazaleh (2005) about the negative effect that the excess of nonstructural carbohydrates has on the level of fat in milk. Finally, there were significant correlations between the average incidence of lameness due to laminitis (Supplementary File, Table 12) and content of starch $(\mathrm{r}=0.837 ; \mathrm{P} \leq 0.01)$, and peNDF $(\mathrm{r}=-0.635 ; \mathrm{P} \leq 0.05)$. This is in agreement with Nocek (1997) about the relationship between the level of non-structural carbohydrates in the dairy cows diet and the incidence of laminitis.

Concerning the income parameters, correlations observed
(Supplementary File, Table 13) fully confirmed the relationship between an efficient ration in technical-economic field and IOFC. In fact, the latter value was positively correlated with: the FE $(r=0.895$; $\mathrm{P} \leq 0.001)$, the production of FCM $(\mathrm{r}=0.912 ; \mathrm{P} \leq 0.001)$, and with the class $3 F C(r=0.793 ; \mathrm{P} \leq 0.01)$. The relationship observed between IOFC and class $2 \mathrm{FC}$ of $\mathrm{FC}(\mathrm{r}=-0.709 ; \mathrm{P} \leq 0.01)$ was negative. The results are coherent with a previous study (Campiotti, 2014) on the relationship between income over feed cost and FE.

\section{Conclusions}

Our results revealed that there were nutritional imbalances in both groups of dairy farms. The imbalance of the carbohydrates level in the diet of Group B influenced mostly Feed Efficiency, and, hence, the farm's profitability. The overall income was also negatively influenced by the protein imbalance, because it led to a deterioration of the indices of reproductive efficiency.

The practical approach used for economic and technical evaluation of the food rationing allowed to identify, to highlight, and to confirm important criticalities caused by an incorrect feeding management. This aspect is of great importance in dairy farms, where it is not always easy to discriminate the underlying causes of a productive result.

This survey work allowed to identify corrective actions, such as to safeguard the economic efficiency of the dairy cattle management, that see significant reductions in profit margins due to the rising cost of raw materials. The IOFC calculation cannot replace the standard economic budget, but represents an immediate approach for the control of the business income as a function of the food cost, predominant item in variable cost of production.

It is hoped that this analysis method will be applied to a larger number of farms to validate the existing relationships among the parameters, in order to prepare an overall assessment scheme capable of highlighting the critical issues of the production process, and supporting the farmer in corporate decisions.

\section{References}

AbuGhazaleh AA, Riley MB, Thies EE, Jenkins TC, 2005. Dilution rate and $\mathrm{pH}$ effects on the conversion of oleic acid to trans C18:1 positional isomers in continuous culture. J. Dairy Sci. 88:4334-41.

Allen MS, 1997. Relationship between fermentation acid production in the rumen and the requirement for physically effective fiber. J. Dairy Sci. 80:1447-62.

AOAC, 1990. Official Methods of analysis. 15th ed. Association of Official Analytical Chemists, Arlington, VA, USA.

Butler WR, 1998. Effect of protein nutrition on ovarian and uterine physiology in dairy cattle. J. Dairy Sci. 81:2523-39.

Campiotti M, 2014. Un'esclusiva analisi economica sulla redditività di 80 stalle. Inf. Agr. 36:20-5.

European Commission, 2004. Regulation (EC) No 853/2004 of the European Parliament and of the Council of 29 April 2004 laying down specific hygiene rules for food of animal origin. In: Official Journal, L 139, 30/4/2004, pp 55-205.

Ferguson JD, Galligan DT, Thomsen N, 1994. Principal descriptors of body condition score in Holstein cows. J Dairy Sci. 77:2695-703.

Grant RJ, 1997. Interactions among forages and nonforage fiber sources. J Dairy Sci. 80:1438-46.

Grant RJ, Cotanch KW, 2005. Physically effective fiber for dairy cows: current perspectives. pp 61-70 in Proc. Cornell Nutr. Conf. for Feed 
Manufacturers. Syracuse, NY, USA.

Hall MB, 2002. Characteristics of manure: what do they mean? pp 141147 Proc. Tri-State Dairy Nutrition Conference, April 16-17, Ft. Wayne, IN, USA.

Heinrichs AJ, Kononoff PJ, 2002. Evaluating particle size of forages and TMRs using the new Penn State forage particle separator. Technical Bulletin, College of Agriculture Science, Cooperative Extension, Penn State University, College, Station, TX, USA, DAS $02-42$.

Hutjens M, 2001. Using dairy efficiency; Wednesday, July 4. Available from: http://ivestocktrail.illinois.edu/dairynet/paperDisplay.cfm? ContentID $=612$

Hutjens MF, 2007. Practical approaches to feed efficiency and applications on the farm. Proc. Penn State Dairy Nutrition Workshop. Penn State University, College, Station, TX, USA.

Hutjens MF, 2010. Feeding economics in 2010. pp 27-28 in Proc. Four State Dairy Nutrition and Management Conference, Dubuque, Iowa, USA.

ISO (International Organization for Standardization), 2000. Whole milk-Determination of milk fat, protein and lactose content. Guide for the operation of mid-infra-red instruments (FIL IDF 141C:2000). International Organization for Standardization,
Geneva, Switzerland.

ISO (International Organization for Standardization), 2004. ISO 14637:2004 (IDF 195: 2004). Milk - Determination of urea content - Enzymatic method using difference in pH (Reference method). International Organization for Standardization, Geneva, Switzerland.

Mariani P, Bonatti P, Sandri S, 1992. Variazioni del contenuto in urea nel latte e suo rapporto con il contenuto di azoto non proteico. Ind. Latte 28:1-3.

Mertens DR, 1997. Creating a system for meeting the fiber requirements of dairy cows. J. Dairy Sci. 80:1463-81.

Nocek JE, 1997. Bovine acidosis: implications on laminitis. J. Dairy Sci. 80:1005-28.

Penn State Extension, 2009. Managing income over feed costs. Dairy risk-management education. Pennsylvania State UniversityCollege of Agricultural Sciences, College, Station, TX, USA.

Roseler DK, Ferguson JD, Sniffen CJ, Herrema J, 1993. Dietary protein degradability effects on plasma and milk urea nitrogen and milk nonprotein nitrogen in Holstein Cows. J. Dairy Sci. 76:525-34.

St-Pierre N, 2008. Managing measures of feed costs: benchmarking physical and economical feed efficiency. Proc. Tri-State Dairy Nutr. Conf. Fort Wayne, IN, USA. 